\title{
Characterization and Clinical Trial of an Innovative High-Speed Lancing Device
}

\author{
Ho Chang ${ }^{1, *}$, Yao-Jen Yeh ${ }^{2}$, Rahnfong Lee ${ }^{3}$, Chia-Chun Lee ${ }^{2}$ and Jenq-Huey Shyu ${ }^{2}$ \\ 1 Graduate Institute of Manufacturing Technology, National Taipei University of Technology, \\ Taipei 10608, Taiwan \\ 2 Graduate Institute of Mechanical and electrical Engineering, National Taipei University of Technology, \\ Taipei 10608, Taiwan; john9317@yahoo.com.tw (Y.-J.Y.); super8860@gmail.com (C.-C.L.); \\ jhshyu@ntut.edu.tw (J.-H.S.) \\ 3 Joinsoon Medical Technology Co., Ltd., New Taipei City 221, Taiwan; eglucose@gmail.com \\ * Correspondence: f10381@ntut.edu.tw; Tel.: +886-2-27712171; Fax: +886-2-27317191
}

Academic Editor: Chien-Hung Liu

Received: 22 February 2016; Accepted: 6 April 2016; Published: 18 April 2016

\begin{abstract}
An innovative high-speed lancing device has a lancet that moves so fast that it is not affected at all by the vibration of its spring, and does not pierce the skin repeatedly, greatly reducing the pain that is caused to diabetes mellitus (DM) patients during blood sampling. As revealed by experimental measurements of the acceleration of a lancet using an accelerometer, the lancet pierces the skin only once. The maximum acceleration and the instant piercing velocity of the lancet are 9.4 times and 1.78 times those of a conventional lancing device, respectively. Meanwhile, the period for which the lancet remains in the skin is $0.014 \mathrm{~s}$ shorter than that of the conventional lancing device. A clinical trial that involved 100 participants yielded statistical results concerning the numeric rating of pain scale (NRS) of pain intensity, which is internationally recognized as the pain with the highest validity, that showed that the NRS of participants who used the innovative high-speed lancing device was 2.65 less than that of those who used the conventional lancing device, and the duration of the pain after blood sampling was 76.1 min shorter.
\end{abstract}

Keywords: lancing device; self-monitoring of blood glucose (SMBG); accelerometer; numeric rating scale (NRS)

\section{Introduction}

In 2015, the number of diabetes mellitus (DM) patients globally exceeded 400 million people. To control their physical condition, DM patients must use a blood glucose meter to perform self-monitoring of blood glucose (SMBG) many times daily. The first step in SMBG is to collect several microliters of blood from a blood capillary. This step requires the use of piercing device to perform an invasive act into a finger or another part of the body. Although only a very small amount of blood is required, the pain and psychological barrier of piercing are the main causes of the failure of general DM patients to fail to perform SMBG as frequently as required by their doctors [1-4].

According to the relevant literature, to reduce the pain that is caused by piercing, many SMBG methods have been developed, as follows. (1) Change the shape and bevel angle of the lancet tip to reduce the size of the wound that is produced by piercing [5,6]. (2) Coat the lancet surface with a special material to reduce the friction between the skin and the lancet and thereby to reduce pain [7]. (3) For patients with various skin conditions, use a lancing device with an adjustable piercing depth or with a small lancet diameter. For example, when sampling blood from babies with thin skin, the depth of piercing depth of the lancet on can be adjusted to reduce the pain caused [8-10]. (4) Change the mechanical design of the lancing device to reduce the vibration of the lancet to cause a smaller 
wound [11-15]. Reducing both the period for which the lancet remains in the skin and the number of piercings of the skin will be very helpful in reducing the pain that is caused by the lancet during blood sampling $[16,17]$. However, the above improvements cannot ensure that the lancet pierces the skin only once after the finger is pricked. Additionally, the piercing velocity, piercing acceleration and duration of puncture have not been analyzed.

The main purpose of this study was to significantly reduce pain in the blood sampling process and shorten the duration of the pain after blood sampling. Motivated by the inadequacy of the relevant literature and defects in the marketed lancing devices, this work develops an innovative high-speed lancing device, which has the characteristic that when it pricks a finger, the lancet pierces the skin only once and remains in the skin for an extremely short period, enabling the sampling of the blood to be completed rapidly. The innovative high-speed lancing device is compared with a common, commercially available lancing device. Furthermore, clinical trials that involve a questionnaire survey to elucidate the pain index are performed to prove further that the innovative high-speed lancing device can reduce the pain level of diabetes patients during the blood sampling process $[18,19]$.

\section{Experimental Details}

\subsection{Lancing Device Principle}

The internal structure of a conventional lancing device comprises a main carrying pillar, a lancet holder and a spring. The compressive force of the spring is used to generate a puncture force. To prevent the lancet from moving as the spring vibrates, the spring of the new lancing device is separated from the lancet holder. The major difference from the conventional lancing device is that the front end of its main carrying pillar is attached to an iron cube of greater mass, which is also connected to the spring to form a single structure. Figure 1 compares the internal structures of the conventional lancing device and the high-speed lancing device. As presented in Figure 1, the high-speed lancing device is designed with its spring separate from its lancet, and an iron cube of greater mass is attached to the spring. The metallic block has a mass of $1.2 \mathrm{~g}$, and the lancet holder has a mass of $0.54 \mathrm{~g}$. The specifications of its spring are those of the marketed lancing device, whose spring is made of piano wire, with a wire diameter of $0.6 \mathrm{~mm}$, an outer diameter of $6.1 \mathrm{~mm}$, an effective coil number of 20, a free length of $32 \mathrm{~mm}$, a $k$ value of $0.113 \mathrm{kgf} / \mathrm{mm}$, and a required load force of $1.2 \mathrm{kgf}$. The conventional device used in this study is Sterolance (SHILI Co., Ltd., Taiwan). The lancet used in the high-speed lancing device has the same specifications as the commercially available lancing device, and both are Easy Touch 28 gauge lancets (MHC Medical Products, Fairfield, OH, USA).

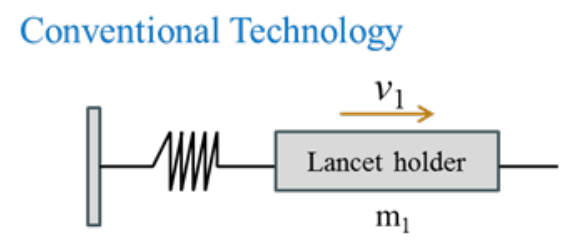

\section{Collision Technology}

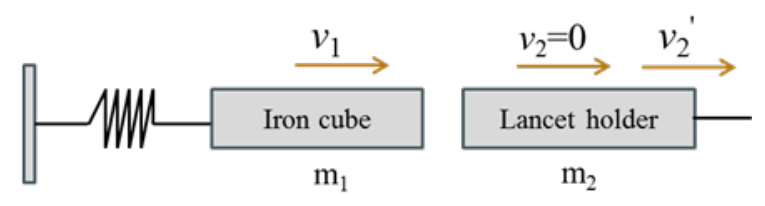

Figure 1. Comparison of main internal structures of conventional lancing device and high-speed lancing device. 
After the high-speed lancing device pricks a finger, its iron cube instantly strikes the lancet holder. From one-dimensional elastic collision theory, Equation (1) gives the velocity of the iron cube $\left(v 1^{\prime}\right)$ and the velocity of lancet holder $\left(v 2^{\prime}\right)$ after striking.

$$
\left\{\begin{array}{c}
v_{1}^{\prime}=\frac{m_{1}-m_{2}}{m_{1}+m_{2}} v_{1}+\frac{2 m_{1}}{m_{1}+m_{2}} v_{2} \\
v_{2}^{\prime}=\frac{2 m_{1}}{m_{1}+m_{2}} v_{1}-\frac{m_{1}-m 2}{m_{1}+m_{2}} v_{2}
\end{array}\right.
$$

Under the special conditions of elastic collision, the following three situations may pertain.

(1) If $m 1=m 2$, then

$$
\left\{\begin{array}{l}
v_{1}^{\prime} \cong v_{1} \\
v_{2}^{\prime} \cong 2 v_{1}
\end{array}\right.
$$

(2) If $m 1>m 2$ and $v 2=0$, then

$$
\left\{\begin{array}{l}
v_{1}^{\prime}=\frac{m_{1}-m_{2}}{m_{1}+m_{2}} v_{1}+\frac{2 m_{1}}{m_{1}+m_{2}} v_{2} \\
v_{2}^{\prime}=\frac{2 m_{1}}{m_{1}+m_{2}} v_{1}-\frac{m_{1}-m 2}{m_{1}+m_{2}} v_{2}
\end{array}\right.
$$

(3) If $m 1>m 2$ and $v 2=0$, then

$$
\left\{\begin{array}{l}
v_{1}^{\prime} \cong v_{1} \\
v_{2}^{\prime} \cong 2 v_{1}
\end{array}\right.
$$

From supposition (3) above, if the mass $(m 1)$ of the iron cube (impactor) considerably exceeds that of the lancet holder $(m 2)$, then after striking, the velocity of lancet holder is close to double the velocity of the conventional lancing device, implying that the lancet of the high-speed lancing device exhibits high-speed motion. Since the spring and the lancet holder are designed to be separate, after the lancing device strikes a finger, its lancet is not affected by the to-and-fro vibration of the spring, and so it pierces the skin only once. Therefore, the duration of the lancet in the skin can be greatly shortened, and the pain is greatly reduced.

In this work, an accelerometer is used to measure the slight motion of the lancet, and acquisition schemes are used to obtain its acceleration. In Figure 2, which presents the setup of the experiment for measuring the acceleration measurement of the lancing device, hop (1) clamps a lancing device (2), and an accelerometer (3) is used to measure the acceleration of the lancet immediately after it strikes the lancing device. The acceleration and velocity data are transmitted to an acquisition device (4), which is connected to a computer (5). Subsequent analysis is performed using Pico Scope 6 (2013, PICO Technology, Eaton Socon, England) and Matlab software packages (Version 7, The MathWorks, Natick, MA, USA, 2014). The sampling interval of the acquisition device, which is set using the analytical software Pico Scope 6, is $2 \mu \mathrm{s}$, so 500,000 samples are taken per second, and continual sampling is used. In addition, each experiment is performed in triplicate, and the mean of the measurements is used in the subsequent calculations. 


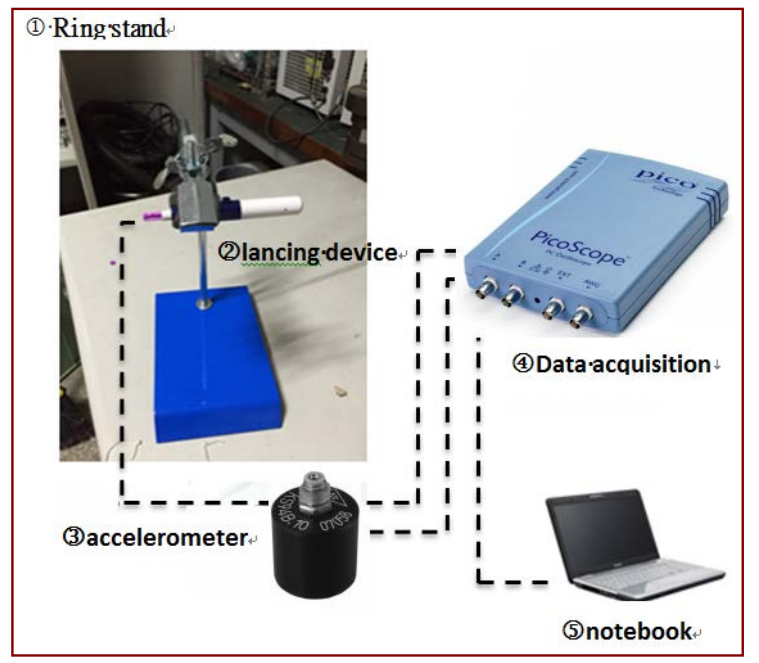

Figure 2. Experimental setup for testing performance of high-speed lancing device.

\subsection{Clinical Study}

The numeric rating scale (NRS) is used herein to evaluate pain. Figure 3 presents the use of the NRS in this study to evaluate pain levels, and the duration of the pain that is associated with the wound. The NRS quantifies the amount of pain felt, as self-assessed by users when they feel the most pain. The NRS runs from 0 to 10 to represent pain levels. A low score indicates that the user feels little pain. The lancing device produces not only acute pain during piercing, but also the pain that is caused by destruction of blood vessels and soft tissue in an inner layer of the skin, which persists for some time following blood sampling. Therefore, the time that is required for wound healing depends on the pricking and piercing conditions. Every period of $15 \mathrm{~min}$ after blood sampling is a potential period of pain. Participants can specify one of seven ranges of the period of pain. Additionally, in the test of the performance of the lancing device, Sample A is a conventional lancing device, and Sample B is the new high-speed lancing device.

A. Numeric Rating Scale (NRS)

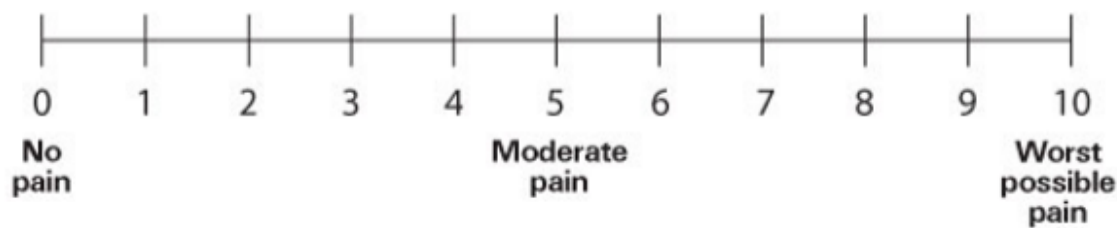

Please point to the position on the line between $0-10$ to indicate how much pain

they are currently feeling

B. How long will the pain last after using this lancing device?

$\square 0 \sim 15 \mathrm{~min} \quad \square 15 \sim 30 \mathrm{~min} \quad \square 30 \sim 60 \mathrm{~min} \quad \square 1 \sim 2 \mathrm{~h} \quad \square 2 \sim 4 \mathrm{~h}$
$\square 4 \sim 6 \mathrm{~h} \quad$ aother: $\quad \mathrm{h}$

Figure 3. Numeric rating scale (NRS) and available periods of pain associated with wound.

One hundred people participated in the clinical trials and questionnaire survey. The DM participants were randomly collected from type 1 (T1DM) and type 2 (T2DM) patients, and were 
all frequent users of SMBG. Visually impaired DM patients and those who had participated in a similar experiment were excluded. In addition, none of the participants had any blood disease, such as anemia, white blood cell disorders, or coagulation abnormalities, etc. Of the 100 participants, 61 were male $(61 \%)$ and 39 were female $(39 \%)$. The mean age of the participants was 32.25 years old $(\mathrm{SD}=21.2)$, and the highest proportion, $30 \%$, were aged 21 to 30 . Table 1 presents the age distribution of the participants.

Table 1. Age distribution of the participants taking clinical trials of pain $(N=100)$.

\begin{tabular}{ccc}
\hline Variables (Age) & Number $(\boldsymbol{n})$ & $\%$ \\
\hline Below 20 & 10 & $10 \%$ \\
$21-30$ & 30 & $30 \%$ \\
$31-40$ & 23 & $23 \%$ \\
$41-50$ & 24 & $24 \%$ \\
$51-60$ & 10 & $10 \%$ \\
Above 61 & 3 & $3 \%$ \\
\hline
\end{tabular}

\section{Results and Discussion}

\subsection{Characterization of Innovative High-Speed Lancing Device}

Figure 4a presents the 3D structurally expanded view of the new lancing device. Figure 4b presents a simulation of its 3D assembly. The actual dimensions of the finished product are a length of $105 \mathrm{~mm}$, an outer diameter of $16 \mathrm{~mm}$, and a mass of $15.5 \mathrm{~g}$.

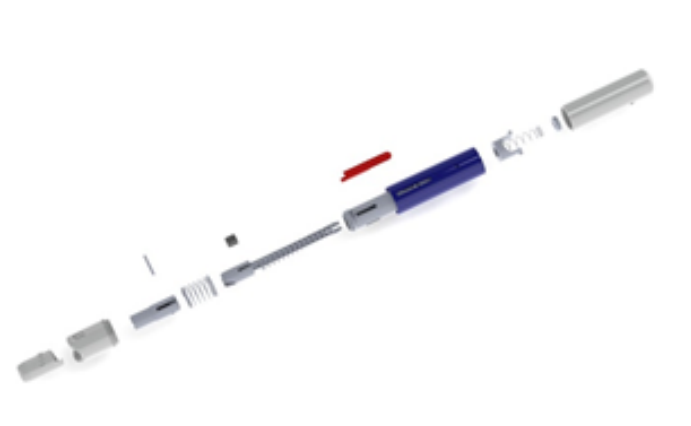

(a)

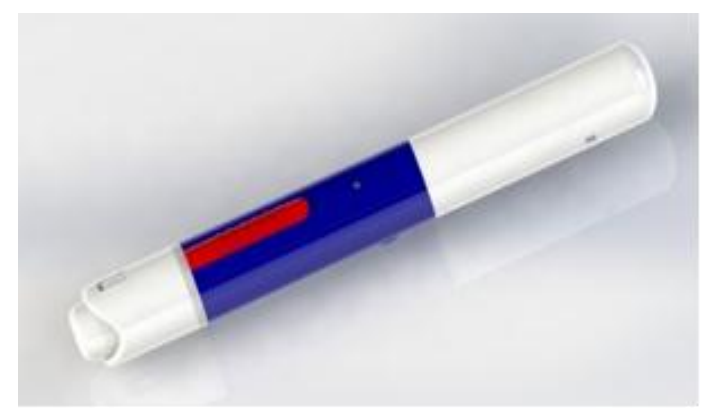

(b)

Figure 4. Innovative high-speed lancing device: (a) structurally expanded view; (b) schematic 3D assembly.

Following the accelerometer experiment, the measured accelerations of the lancet after the lancing devices are used to prick fingers are compared, as presented in Figure 5a. Figure 5a reveals that the acceleration of the conventional lancing device is $0.236 \mathrm{~m} / \mathrm{s}^{2}$, and the lancet clearly vibrates four times as the spring vibrates. The high-speed lancing device has an acceleration of $2.23 \mathrm{~m} / \mathrm{s}^{2}$, which is 9.4 times that of the conventional lancing device, and its lancet reaches a stable state very rapidly after the first piercing. Integrating the acceleration signals with respect to time in Matlab yields velocity in the time domain. As presented in Figure $5 b$, the maximum velocity with which the conventional lancing device pierces the skin is $1.468 \mathrm{~m} / \mathrm{s}$, and the maximum velocity at which the high-speed lancing device does so is $2.62 \mathrm{~m} / \mathrm{s}$, which is 1.78 times the former. From here, the developed high-speed lancing device has an iron cube of greater mass to strike the lancet holder, so the lancet pierces at a higher speed. Integrating velocity with respect to time yields the relationship between the displacement of lancet and time, which is plotted in Figure 5c. In Figure 5c, the displacement of $5.5 \mathrm{~mm}$ corresponds to the position where the lancing device, attached to a rotational cap, comes in contact with the skin. As revealed by the figure, the conventional lancing device pierces the skin three times, and the lancet 
remains in the skin for a total duration of $0.018 \mathrm{~s}$. The lancet of the high-speed lancing device pierces the skin only once, and remains in the skin for only $0.004 \mathrm{~s}$, which is $0.014 \mathrm{~s}$ less than the former value. Since the lancet of the new high-speed lancing device pierces the skin only once and stays in the skin for a much shorter period than does that of the conventional device, the pain is expected to be much less and the healing time of the wound shorter. The commonly marketed lancing device is sold at USD 13-50. The prepared high-speed lancing device, due to its simple structure, has its cost lower than conventional lancing device, but its functions surpass all other lancing devices produced by internationally famous pharmaceutical company.

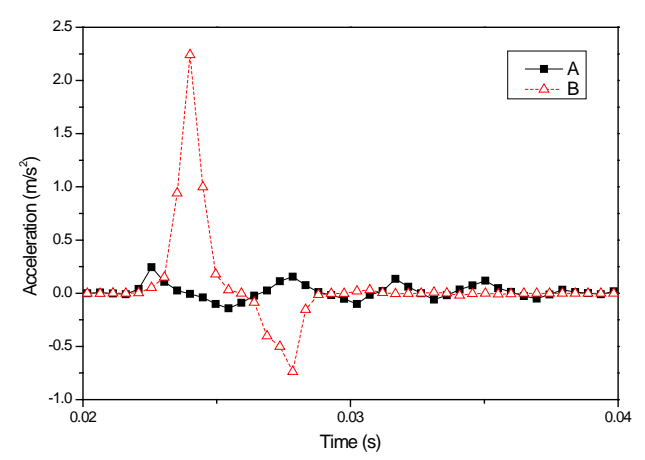

(a)

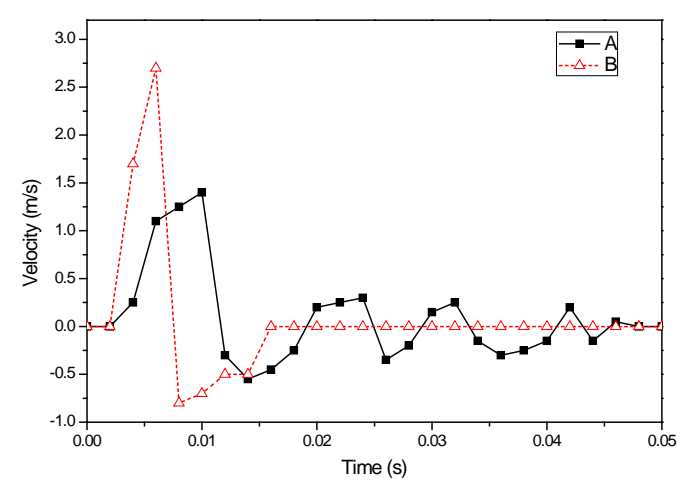

(b)

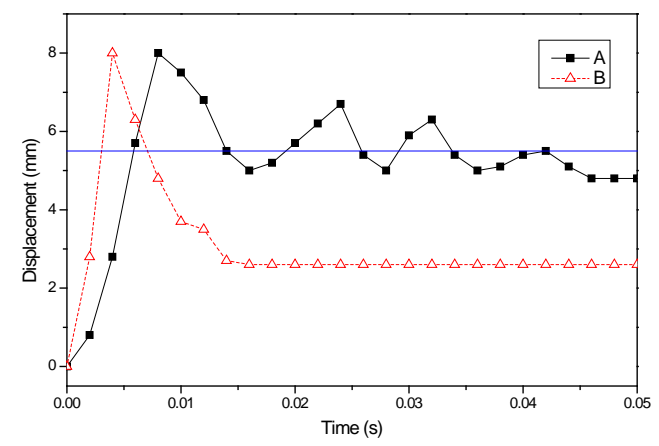

(c)

Figure 5. Relationships between (a) acceleration, (b) velocity, (c) displacement, and time after two types kinds of lancing device prick a finger.

\subsection{Results of Clinical Trial}

The test results were analyzed in SPSS. Table 2 presents the statistical results concerning the pain index and the duration of pain in the experiment in which both types of lancing device were used. 
Figure 6a compares the values of the pain index on the numeric rating scale (NRS) obtained using the two types of lancing device. From Table 2 and Figure 6a, the mean NRS score for Sample A is 6.46, and that for Sample B is 3.81, which is 2.65 less than the former value. Therefore, the conventional lancing device gives participants greater pain, whereas the high-speed lancing device causes only slight pain. Most participants selected an NRS score of 2 . Table 2 reveals that the $95 \%$ confidence intervals for Samples A and B are 6.01-6.90 and 3.24-4.35, respectively. Figure 6b compares the durations of pain time after the two types of lancing device were used for sampling blood. When Sample A was used for sampling blood, the wound caused no pain after an average of $129.5 \mathrm{~min}$. When Sample B was used, the pain completely disappeared approximately $53.4 \mathrm{~min}$ after blood sampling-76.1 min sooner than when Sample A was used. The duration of the pain was therefore only 0.41 times that obtained when Sample A was used. Most participants stated that pain disappeared $30 \mathrm{~min}$ after blood sampling. Table 2 reveals that the 95\% confidence intervals for Samples A and B are 83.9-160 and 37.9-68.8, respectively. As proved by the above pain evaluation experiment, not only is the pain index obtained using the new high-speed lancing device much lower than that obtained using the conventional lancing device, but also the duration of the pain was much lower.

Table 2. Statistical results of pain experiment using two types of lancing device.

\begin{tabular}{ccc}
\hline Variables & Pain levelM \pm SE & 95\% CI \\
\hline NRS & & \\
Sample A & $6.46 \pm 0.22$ & $6.01-6.90$ \\
Sample B & $3.81 \pm 0.27$ & $3.24-4.35$ \\
\hline Pain duration time & & \\
Sample A & $129.5 \pm 15$ & $83.9-160$ \\
Sample B & $53.4 \pm 7.67$ & $37.9-68.8$ \\
\hline
\end{tabular}

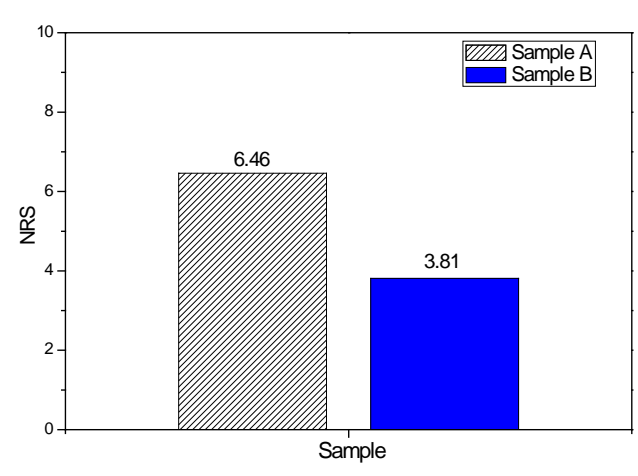

(a)

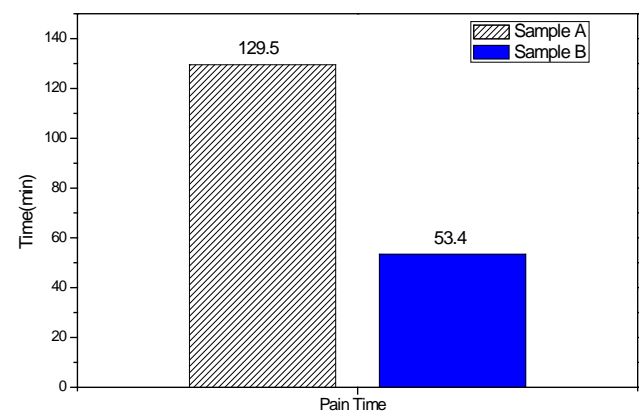

(b)

Figure 6. Comparison of (a) pain index, (b) duration of pain after blood sampling in pain evaluation experiment using two types of lancing device.

\section{Conclusions}

The new high-speed lancing device effectively overcomes the shortcomings of the marketed conventional lancing device, which pierces the skin several times owing to vibration of the spring, and so it causes much less pain in the blood sampling process. Measurements of the acceleration of this innovative high-speed lancing device and the results of a clinical trial support the following conclusions.

(1) After the conventional lancing device pricks a finger, its lancet pierces the skin three times, whereas the lancet of the new high-speed lancing device pierces the skin only once. The acceleration and velocity of the lancet of the new high-speed lancing device are 9.4 and 1.78 times those of the 
conventional lancing device, respectively. The lancet of the innovative high-speed lancing stays in the skin for $0.014 \mathrm{~s}$ less than that of the conventional lancing device.

(2) From the statistical results of the clinical trials, the mean NRS score for the pain of the users of the new high-speed lancing device is 3.81, which is 2.65 less than that of those of the conventional lancing device, and the duration of the pain after blood sampling is $53.4 \mathrm{~min}$, which is 0.41 times that obtained using the conventional lancing device.

Acknowledgments: The authors would like to thank the Ministry of Science and Technology of the Republic of China, Taiwan, for financially supporting this research under Contract No. NSC 102-2221-E-027-012.

Author Contributions: Yao-Jen Yeh is a consultant for, and supervised, this research. Ho Chang is the main author of the manuscript and advised on the experiments. Rahnfong Lee and Jenq-Huey Shyu conceived and designed the simulation. Chia-Chun Lee carried out the experiments and assisted in the research.

Conflicts of Interest: The authors declare no conflict of interest.

\section{References}

1. Laffel, L. Improved accuracy of continuous glucose monitoring systems in pediatric patients with diabetes mellitus: Results from two studies. Diabetes Technol. Ther. 2016, 18, S223-S233. [CrossRef] [PubMed]

2. Klonoff, D.C. Improving the safety of blood glucose monitoring. J. Diabetes Sci. Technol. 2011, 5, 1307-1311. [CrossRef] [PubMed]

3. Heinemann, L. Finger pricking and pain: A never ending story. J. Diabet. Sci. Technol. 2008, 2, 919-921. [CrossRef]

4. Heinemann, L.; Boecker, D. Lancing: Quo vadis? J. Diabetes Sci. Technol. 2011, 5, 996-981. [CrossRef]

5. Wang, Y.; Chen, R.K.; Tai, B.L.; McLaughlin, P.W.; Shih, A.J. Optimal needle design for minimal insertion force and bevel length. Med. Eng. Phys. 2014, 36, 1093-1100. [CrossRef] [PubMed]

6. Wang, Y.; Tai, B.L.; Chen, B.L.; Shih, A.J. The needle with lancet point: Geometry for needle tip grinding and tissue insertion force. J. Manuf. Sci. Eng. 2013. [CrossRef]

7. Flora, B.A.; Ruggiero, J.E. Multiple Tip Lancet. 1771112 A2, 11 April 2007.

8. Fruhstorfer, H.; Schmelzeisen-Redeker, G.; Weiss, T. Capillary blood sampling: Relation between lancet diameter, lancing pain and blood volume. Eur. J. Pain 1999, 3, 283-286. [CrossRef]

9. Arendt-Nielsen, L.; Egekvist, H.; Bjerring, P. Pain following controlled cutaneous insertion of needles with different diameters. Somatosens. Motor Res. 2006, 23, 37-43. [CrossRef] [PubMed]

10. Christopher, R. Lancing Device. 20080082117 A1, 3 April 2008.

11. Kuhr, H.J.; Forster, R. Device for Withdrawing Blood for Diagnostic Applications. 7322998 B2, 29 January 2008.

12. Robert, U. Lancing Device with Dampener. 1810616 B1, 2 December 2009.

13. Prais, E.; Sams, R.S.; Yao, S. Lancing Device. 20140276221 A1, 18 September 2014.

14. Ruan, T.; Hoover, S. Lancing Device. 20140107689 A1, 17 April 2014.

15. Lai, S.K.; Yeo, C.K. Lancing Device for Minimizing Pain. 20100145377 A1, 10 June 2010.

16. Kocher, S.; Tshiang, T.J.K.; Koubek, R. Comparison of lancing devices for self-monitoring of blood glucose regarding lancing pain. J. Diabetes Sci. Technol. 2009, 3, 1136-1143. [CrossRef] [PubMed]

17. Ginsberg, B.H.; Shemain, A.; Pynes, M.K.; Wallace, D.A.; Pineau, M. Evaluating the OneTouch ${ }^{\circledR}$ Delica $^{\mathrm{TM}}$ : A Low-pain lancing system for self-monitoring of blood glucose. Postgrad. Med. 2011, 123, 92-98. [CrossRef] [PubMed]

18. Huskisson, E.C. Measurement of pain. Lancet 1974, 2, 1127-1131. [CrossRef]

19. Liao, Y.M. Validation of the Chinese Version Behavioral Pain Scale. Master Thesis, Taipei Medical University, Taipei, Taiwan, April 2007. 